\title{
KUIDAS SERVEERIDA AJALOOLIST ARHITEKTUURI? MÄRKMEID JA MÄRKUSI "Eesti AJALUGU II: EESTI KESKAEG" ARHITEKTUURILÕIKUDE KOHTA
}

Üks korralik ajalooraamat vaatleb teemasid seinast seina. Seetõttu ei puudu sealt ka arhitektuuri- ja kunstikäsitlused, kuid enamasti ei raatsita palju ruumi sellise perifeerse valdkonna jaoks kulutada. Nii on talitanud ka "Eesti ajalugu II". Sellise etteantud vähese mahu juures on kaunis lootusetu anda mingitki pilti Eesti ala keskaegsest ehituskunstist. Olukorra teeb keerulisemaks seegi, et vastavalt raamatu struktuurile on arhitektuuri teema jupitatud mitmete alajaotuste vahel.

Näiteks linnakirikud, maakirikud ja kloostrikirikud on vahel väga lähedased sugulased, kuid vähemalt selle raamatu kaante vahel ei kohtu nad kordagi. Küll ei olda sellise temaatilise jaotusega järjekindel. Üldjuhul on teoses arhitektuurimaterjal jagatud erinevate keskkondade - maa ja linna - vahel. Erand on tehtud kloostritele, mida vaadeldakse üheskoos. Ei arva, et selline otsus on õige, kusjuures küsimus pole formaalses jaotuses. Mitmete ordude teke ja tegevussfäär oli ikka seotud linnakeskkonnaga. Sootuks teine oli olukord argimelust eemaletõmbunud tsistertslastega. Nii on ordude ja nende kloostrite erinevus vahel märksa suurem kui näiteks linnas ja maal asuvate parohhiaalkirikute puhul. Aga sellega küsitavused veel ei lõppe. Raamatus on väga korralik vaimulike ordude ülevaade, mille puhul paistab olevat mängus Tiina Kala käsi. Seevastu kloostreid puudutavad väikesed arhitektuurilõigud on hoopis kuskil mujal. Ilmselt olnuks ainumõistlik lülitada need üheks tervikuks. Eriti võitnuks sellega frantsisklased. Nende arhitektuuri kohta teame Eestis imevähe ning paratamatult jääb selleteemaline iseseisev 19-realine lõik (lk 329) väheütlevaks. Sarnaselt on ka ordulinnustega. Juhan Kreem on enda ordulinnuste-peatükis kramplikult hoidunud väiksemastki vihjest arhitektuurile - sest seda teemat käsitletakse alles kakssada lehekülge tagapool. Ma ei ole kindel, et lugeja sellisest hakkimisest palju võidab.

Sellist ülevaadet kirjutama asudes peab vägagi täpselt endale selgeks tegema, millist sõnumit, missuguseid üldistusi ja fakte lugejale esmajoones edastada. Igatahes tuleb lähtuda eeldusest, et lugeja saab teabe kätte ilma, et ta peaks kõrvale otsima riiulitäit abikirjandust. Samuti peab väga täpselt mõtlema, kes on teose sihtgrupp. Kes on see "keskmine lugeja", missugused on tema eeldatavad eelteadmised ja mida tuleb tingimata lahti seletada? 
Tundub, et käesoleva teose puhul alati sellele mõeldud ei ole. Selline mulje tekib tervet raamatut lehitsedes, näiteid võib tuua ka arhitektuuri osast. Nii on näiteks linnakäsitluses juttu diele-dornse tüüpi elamust (lk 343), kuid mida see tähendab, seda põhitekst ei selgita. Seevastu basiilika puhul algab ülevaade sellest, kuidas see oli kasutusel juba vanadel roomlastel ning järgnevalt varakristlastel (lk 344). Need teadmised peaksid kuuluma kunstiajaloo stiilikursusesse, mida käesolevas raamatus korrata poleks vaja. Ruumi on niikuinii imevähe.

Kersti Markus on korduvalt nimetanud, et meie vanema kunsti uurimisel on hakatud kasutama uusi meetodeid ja lähenemisi. Tulevikus peaksid need asetama ka kirikuehituse Eestis hoopis teise valgusesse. Sellega on ühtlasi vastandutud vanamoelistele stiilianalüüsijatele, kelle hulka kuulus näiteks Villem Raam. ${ }^{5}$ Loomulikult on keskaja kunsti huviline nüüd põnevil: kuidas need uuenenud teaduse lapsukesed juba kaela kannavad. Alljärgnevas lühivaatluses on puudutatud peamiselt materjali, mis on raamatus esitatud. Ainult üksikjuhtudel on osutatud sellele, mis võinuks seal veel olla.

MAAKIRIKUD. Meie arhitektuuriajaloolaste käsitlustes on kirik reeglina üks müüride, võlvide ja igasuguste detailide surnud kogum. Kersti Markuse miniülevaate vooruseks (õigemini: meie oludes tõeliseks uuenduseks) on see, et kirikut vaadeldakse oma tegutsemises ja püütakse seletada, kuidas seda kasutati ja milleks üks või teine element üldse olemas oli. Muidugi eeldanuks siingi mõne mõiste lahtiseletamist. Nii saame teada, et koguduseja altariruumi võis eraldada võre (lk 321). Iga "Viimse reliikvia" austaja teab väga hästi, kuidas selline asi välja nägi. Küll ei tarvitsenud vahevõre või lettner alati tähendada rauast konstruktsiooni, vaid võis olla ka massiivne kivist rajatis. Näiteks V. Raam ei välistanud seda Valjala kiriku puhul.

Väike lõik vaatleb ka kirikutorne ja nendib, et need olid üldjuhul läänes ( $(\mathrm{k}$ 327). Ise alustaksin hoopis sellest, et erinevalt tänasest tavaarusaamast polnud kirikutorn keskajal sugugi enesestmõistetav. Võiks teadaolevad andmed kokku panna ja üles lugeda, kas enne 15. sajandit oli rohkem torniga või tornita kirikuid. Siia lisandub detail, et kuni 16. sajandi alguseni polnud ühelgi meie toomkirikul korralikke torne - alles siis sai Tartu toom oma kaksiktornid.

Ühe terminiga ei saa küll nõustuda. Nimelt on raamatus teemaks ka "lihtne ühelööviline saalkirik, kus koor moodustub pikihoone idapoolsest võlvikust". Nimetatud on Haapsalu eeskujul ehitatud Kullamaa kirikut ja rühma Harjumaa pühakodasid (lk 321-322). On omaette küsimus, ka on

Kersti Markus, "Armin Tuulse ja kirikute uurimine”, Kuhu lähed, Eesti kunstiteadus. Pühendatud Armin Tuulse 10o. sünniaastapäevale, Kunstiteaduslikke Uurimusi, 3 (17) (Tallinn: Eesti Kunstiteadlaste Ühing, 2008), 36-37. 
õige kõiki neid pelgalt plaaniskeemi alusel ühe mütsi alla panna: Haapsalu toomkiriku ja Põhja-Eesti kastehitiste taga näikse olevat sootuks erinevad ideoloogiad. Hetkel häirib hoopis kasutatud termin - saalkirik. Saksa keeleruumis on Saalkirche seesama, mida meie nimetame ühelööviliseks kirikuks. See et tarvitse sugugi koosneda ühest liigendamata ruumist: üksikosad võivad olla omavahel astendatud nii kõrguses kui ka laiuses. Samuti pole välistatud apsiid ega muud lisandid. ${ }^{6}$ Seega vaatluse all olev kastilaadne ehitis on ühelöövilise ehk saalkiriku üks erijuht.

Peatükis on siinkirjutaja jaoks ka üks uudne ja põnev teade. Nimelt ei seisnud inimesed Järvamaa kirikutes näoga peaaltari suunas, vaid paiknesid hoopis põhja-lõunasuunaliselt ( $\mathrm{lk}$ 324). Niivõrd uudse teabe puhul võinuks lisada selle tuletuskäigu kohta väikesegi vihje.

PlaAnID. Nii kirikute kui ka järgnevalt linnuste kohta on esitatud väike valik plaane. Peale ühe erandi on tegemist kolmkümmend aastat tagasi koguteose "Eesti arhitektuur" jaoks valminud joonistega. Toona oli see tõeline hoogtöö ning nii mõnelgi korral oli tulemustes vasturääkivusi ja vigu. Joonistel on müüre erinevalt tähistatud: nii on võimalik näidata kuni nelja ehitusetappi, millele osutab ka raamatujoonistele lisatud annotatsioon. Selliselt koondatud plaanide puhul tuleb aga eeldada, et kogu materjali puhul on samad mängureeglid, kuid paraku see nii ei ole. Joonistelt selgub, et Ambla piilarid on sekundaarsed. Tegelikult on sarnaselt kulgenud ka Nõo kiriku ehitamine, kuid esitatud plaan seda ei kajasta. Edasi näeme, et Keila ja Muhu kirikud sisaldavad kolme ehituslikku ladestust - erinevalt Valjalast, mille koor ja pikihoone on plaani andmeil valminud üheskoos (!). Kõige rohkem küsimusi tekitab aga Oleviste kirik, mille pikihoone koos torniga on värvitud ühetaoliselt mustaks - järelikult on kõik korraga ehitatud. Kohe meenub Rasmus Kangropooli väide, et külglöövid olid algselt läänetravee jagu lühemad. Kas see seisukoht on nüüd kummutatud? Samuti jääb vaatajale ilmselt arusaamatuks, miks Oleviste pikihoone rajamisel lõunalöövi piilarid nii kööbakalt maha märgiti. Vaevalt taipab lugeja, et must värv joonisel peidab Oleviste pikihoone tervelt kahe sajandi pikkust ehituslugu.

Need märkused võivad näida näägutamisena pisidetailide kallal. Joonised aga pole arhitektuuriajaloo puhul pelgalt tekstilehekülge elavdavad ilupildid, vaid tõsine töövahend ja oluline informatsiooniallikas. Ja siin ei piisa vabandusest, et omal ajal keegi nii joonistas.

KLOOSTER. Jätkuvalt arvan, et Eestis on kaks keskaegset, Euroopa mastaapides unikaalset ehitusmälestist: Tartu Jaani kirik ja Padise klooster. Padisele on pühendatud vaid veerand lehekülge. Saame teada, et sealne 1448. aastal

$6 \quad$ Lexikon der Kunst IV (Leipzig: Seemann, 1977), 252. 
pühitsetud kirik oli lihtne saalruum ning kuskil oli keldrikabeli kesksammas (lk 327). Sellest ei saa kuigivõrd aru, mis seal Padisel ikkagi on - oleks vähemalt plaangi! Kloostri erakordsuse adumisest ma ei räägigi. Desorienteeriv on Padise fotole lisatud märge, et Liivimaa kloostrid "ei järginud täiel määral ordu ehitusreegleid” (lk 328). Tuleb teha selget vahet reeglitel ja traditsioonil. Tsistertslaste reeglistikus on ehituse teemalisi ettekirjutisi imevähe ning vähemalt enamikku neist pole Padisel eiratud. Ordu omanäolise arhitektuuri taga on aga hoopis traditsioonid, mis reeglites ei kajastu. Padisel (samuti ka Kärknas) pole järgitud tsistertslaste planeeringutavasid, vaid mindud isepäiselt oma teed. Ja veel - kuidagi ei tahaks leppida sellega, et kabeleid (seal oli tingimata ka altar!) tituleeritakse kõrvalruumideks (lk 327).

Linnades tegutsenud kloostrite puhul oleks tahtnud näha suuremat järjekindlust. Kui ühel juhul osutatakse mingisugusele olulisele tunnusele, siis samasugust asja teise kloostri juures ei tohiks maha vaikida. Nii on Pirita puhul märgitud, et nunnad olid rõdul (lk 330). Tegelikult oli nii enamiku ordude naiskloostrites. Nii oli ka naistsistertslaste puhul ning kahtlemata ka Tallinna Mihkli kloostris. Täna annab kiriku omaaegsele kasutusstruktuurile väikese vihje üksnes elegantne nurgaärkel.

Tallinna dominiiklaste kiriku puhul loeme, et selle läänepoolne osa kuulus ilmikutele (lk 329). Ilmselt järeldab tavalugeja, et kõik oli nagu ühes kogudusekirikus, kus samuti oli pikihoone ilmikute tarbeks. Siin oleks küll oodanud selgitust, et kerjusmunkade (dominiiklaste ja frantsisklaste) kirikud olid ennekõike avalikkusele suunatud jutlusruumid. Aga nagu juba eespool märkisime, olnuks ilmselt õigem kogu see temaatika liita peatükiga "Vaimulikud ordud".

LINNUSTE osa valmistas esmalt väikese üllatuse: siin on aluseks võetud tüpoloogiline jaotus, mille on esitanud A. Tuulse, V. Raam ja viimati K. Alttoa. Juba 1990. aastail tunnistasid Põhja-Euroopa kastelloloogid tüpoloogilise lähenemise lootusetult vanamoeliseks. Küll arvan jätkuvalt, et vähemalt Eesti ala linnuste puhul toimib see hästi tänagi.

Siingi keskenduksin ennekõike detailidele. Ma ei ole kindel, kas Haapsalu kastellitüüpi linnust rajades pidi piiskop midagi kaasaegset otsides ordumeeste poole kiikama (lk 335). Tegelikult on kastelli “maaletoojaks" Vana-Liivimaale ikka piiskoppide leer - pean siin silmas Holme (Mārtiņsala) kastelli Daugava saarel. Muide, seal oli linnuse kõrval ka kirik, mille mõned omapärased lahendused viitavad geneetilistele sidemetele Haapsalu toomkirikuga. Kas see on juhuste kokkulangevus või oli siin midagi rohkemat? 
Autor nimetab ka puust tara ja kraaviga kindlustatud mõisamaju ja osutab Piigastele (lk 338). Mina pole siiamaani kindel, mis seal Piigastes ikkagi oli: kas kindlustatud koht või hoopis tellisepõletusahi.

Üksikmärkustega võiks jätkata, kuid esmajoones juhiksin tähelepanu väikesele sissejuhatavale lõigule. Seal on nimetatud, et linnused olid ka võimu- ja halduskeskused, elamud, laohooned ja isanda võimu näitlikustajad (lk 334). Nende märksõnade taga on lausa hunnikus põnevaid teemasid. Ainuüksi mõnegi lühikene avamine-markeerimine oleks kahtlemata oluliselt avardanud ettekujutust sellest, mis asi see Eesti keskaegne linnus ikkagi võis olla.

Aga ka linnuste puhul ei saa mööda plaanidest (lk 335). Vastseliina juures on kasutatud kahte erinevat tähistust. Tegelikult on seal olnud viis või rohkem suuremat ehitusetappi. Hea seegi, et plaanil joonistub selgelt välja algne tuumik - massiivne tornlinnus. Helme linnuses on plaani andmeil kõik korraga ehitatud. Isegi põgus varemete vaatlus näitab, et nii see siiski ei olnud. Hoopis desinformeeriv on aga Kuressaare linnuse plaan. Siin on mustaga (väidetavalt vanim ehitusetapp!) tähistatud tervelt neli suuremat ladestust linnuse kujunemisloos: nurgatorniga (hilisem Sturvolt) kastell, konvendihoone, esimene eeslinnus ning lõpuks täiendav müür eeslinnuse merepoolsel küljel. Plaanil on ka üks suurem poolümar moodustis: konfiguratsiooni põhjal tahaks siit välja lugeda korralikku torni, mis miskipärast paikneb äraspidi. Tegelikult oli algjoonisel selle koha peal märgitud tagasihoidlik kaev, mis eeslinnusele uue müüri lisamisel jäi servapidi ehituse alla.

LINNADE alapeatükk algab miniatuurse sissejuhatava lõiguga. Lugeja peaks selle põhjal veenduma, et nii Tallinn kui ka Tartu olid üks tervik: ei olnud siin mingit eraldi administratsioonidega üla- ja all-linna. Käsitluse põhimaht on aga antud linnakindlustustele ning lõpuks peatutakse ka elamul. Küll on linn kui nn füüsiline tervik - see tänavate ja ehitiste kogum tähelepanu alt täiesti välja jäänud. Muidugi on tõsi, et meie kunstiajaloolased ei armasta kuigivõrd linnaehituse teemat. See on ka mõistetav: tegemist on ääretult raske valdkonnaga. Küll leidub meie keskaegse linnaplaani vägagi korralik käsitlus Lilian Hansari doktoritöös. ${ }^{7}$ Üksnes selle põhjal saanuks Eesti keskaegsete linnade planeeringute teemal kirjutada kasvõi leheküljelise ülevaate.

Linnakindlustuste puhul kõneldakse peamiselt Tallinnast. See on ka arusaadav: nii ulatuslikult säilinud kindlustuste kompleks on harukordne terves Põhja-Euroopas. Lisaks on olemas Rein Zobeli põhjalikud uuringud. Teiste

Lilian Hansar, Linnast muinsuskaitsealaks. Linnaehituslike struktuuride muutused Eesti väikelinnades 13.-20. sajandil, Dissertationes Academiae Artium Estoniae, 4 (Tallinn: Eesti Kunstiakadeemia, 2010). 
linnade puhul on ennekõike loendatud, mitu väravat ja torni ühel või teisel linnal oli. Sellised numbrid kuuluvad ennekõike mälumängurite maailma, arhitektuuriloole lisavad need vähe. Sest ega näiteks väravate arv ei kajasta alati linna rikkust ega kaitsevõimet: siin olid määravaks hoopis muud faktorid. Või oli Pärnu oma kuue väravaga poole vägevam Viljandist, mis pidi leppima kolme väravaga? Mõnel pool on nimetatud ka tornide kuju, näiteks Tartus oli ka üks ümar nurgatorn (lk 342). Küll ei saa ma aru, kas on silmas peetud Moskva või Pasatorni - oli ju Tartus tegelikult kaks ümara plaaniga suurtükitorni. Selliste üldandmete kõrval on iga linna puhul lisatud mõned repliigid üksikdetailide kohta. Juhtumisi puudutavad mitmed neist teemasid, millest olen kunagi pisut kirjutanud.

Tartu puhul leidub märge ( $1 \mathrm{k} \mathrm{339):} \mathrm{"Pole} \mathrm{teada,} \mathrm{kas} \mathrm{Toomemäe} \mathrm{piiskopiala}$ ja all-linna vahel oli vahemüür või mitte”. Arvan, et ühes artiklis olen piisavalt põhjendanud, miks Tartus vahemüüri ei saanud olla. Nimelt saanuks sellist müüri ehitada üksnes Toomemäe või -neemiku jalamile. Sel juhul oleks müüril olnud ainult üks otstarve: pakkuda tõhusat varjet Toomemäe piirajale. Kahtlen, kas nii rumalat fortifikaatorit õnnestunuks keskajal leida.

Viljandi linna kaitseehitiste kohta on sedastus, et need ei teinud keskaja vältel läbi olulisi uuendusi ja olid keskaja lõpuks suuresti iganenud (lk 343). Tuleb küll lisada, et millalgi 1500. aasta paiku või pisut hiljem on linna idaküljele ehitatud võimas sõõrümara põhiplaaniga suurtükitorn. Umbkaudu samal ajal on rekonstrueeritud ka Riia värav, mille skeemi olen kunagi publitseerinud. Tegemist on küllaltki väikese rajatisega, kuid rakendatud on vägagi kaasaegseid kaitseprintsiipe. Võrreldes selle väravaga esindasid Tallinna toonased mahukad väravakompleksid ikkagi fortifikatsioonikunsti eilset päeva.

Uus-Pärnu puhul on märgitud, et siin oli lisaks linnamüürile ka muldvall (lk 342). Need vallid, kus olid ka laskepesad kahuritele, on tõesti põnevad - tegemist on omalaadsete bastionide eelsete muldkindlustustega. Olen kunagi pakkunud välja oletuse, et siia võis olla segatud Andreas Målare nimelt on teated, et see Rootsi ehitusmeister tegeles 1564. aastal Pärnu kindlustusprobleemidega. Sel juhul jääb aga valli-teema vaadeldava raamatu ajalistest piiridest välja.

Muidugi pole välistatud, et hilisemad uurimised on mõne mu omaaegse väite või oletuse kummutanud. Küll ei arva, et nimetatud detailid on käesoleva raamatu kontekstis olulised. Kui aga selliseid seiku siiski esitatakse, siis eeldaks ka nende paikapidavust.

Aga üks tõsine etteheide raamatu tegijatele. Võinuks eeskuju võtta Hans Kruusi toimetatud eelkäijast ning avaldada mingigi hulga keskaegsete linnade plaane. Tingitud raamatu struktuurist on andmed ühe või teise linna 
kohta kildudena laiali laotanud. Näiteks Tartu puhul saame teada, et linnas olid Toomkirik, Maarja ja Jaani kirik (lk 344), neli kloostrit või konventi (lk 264-270), kaks vene kaupmeeste kirikut (lk 206) ja gildihooned (lk 350). Kardetavasti enamik lugejatest nende andmete põhjal tervikpilti kokku ei pane. Selleks on ikka vajalik plaan, millelt muu hulgas selguks, kus miski oli. Niimoodi saanuks ühtlasi delegeerida tornide-väravate üleslugemise hoopis lugejale.

Edasi on teemaks linnaelamud (lk 343). Saame teada, et maju tehti nii kivist kui ka puust. Kivimaja oli kallim, tellis polnud odav ja ka katusekivi oli kallis. Domineerisid diele-dornse tüüpi elamud (lk 343). Mida see tähendab, seda põhitekst ei selgita. Alles järgmisel leheküljel paikneva illustratsiooni annotatsioonist saame teada, et dornse oli köetav eluruum, diele aga oli kõrge ja seal nurgas oli mantelkorstna-alune köök. ${ }^{8}$ Kas ja mida aga dieles peale kokkamise veel tehti, ei selgu. Kogu see jutt on nii üldine, et seda võiks silpigi muutmata kasutada kümnete Põhja-Euroopa kaubalinnade puhul. Palju põnevam oleks teada saada Tallinna elamute ja järelikult ka linnapildi erisuste kohta.

LINNAKIRIKUTE maht on õnnetu: nende arhitektuurile on jagunud vaevalt kolmveerand lehekülge. Sellestki hõlmab kolmandiku selgitus basiilika kohta, millest eelnevalt juba kõnelesime. Samal ajal pole kogu raamatus sõnagi kodakiriku selgituseks. Arvan, et see oleks vajalikumgi - igatahes sõna "koda" tähenduse teadmisest siin ei piisa. Kogu basiilika teema Eestis mahub aga ühte lausesse (lk 344): sellised olevat olnud 14. sajandil valminud Tartu toom ja Jaani kirik ning 15. sajandil ümber ehitatud Oleviste ja Niguliste Tallinnas. Seda on pisut vähe ning ega see pilt päris nii lineaarne polnud. Nii Riia kui ka Tartu toomkirikut alustati basiilikana, vahepeal otsustati kodakiriku kasuks ning lõpptulemuseks oli taas basiilika.

Arvan, et Tallinna juhtum vajanuks väikest selgitust. Euroopa üldisi arenguid arvestades on sealne pilt kummaline, sest rikkaks saanud linnakodanlus eelistas üldjuhul kodakirikut. Valiku taga polnud finantskaalutlused, vaid pigem ideoloogia: nii püüti vastanduda "kõrgetele" seisustele, kelle märgiks kirikuehituse vallas oli eelkõige basilikaalne katedraal. Tallinna kooriümbriskäiguga basiilikate puhul võib esmapilgul jääda mulje, et siinsed pürjelid on oma iseteadvuse väljendamiseks valinud täiesti valed märksõnad. Tegelikult pole tegu tallinlaste hälbimuse, vaid rahakate hansalinnade omapäise

\footnotetext{
8 Vahest oleks meilgi mõistlikjärgida sakslasi, kes vaadeldava elamutüübi puhul kasutavad lihtsalt mõistet Dielehaus. Niisiis diele-maja või isegi diilemaja. See dornse ei tähenda ju muud kui köetavat eluruumi, mille olemasolu meie kliimavööndis pole tarvilik eraldi rõhutada.
} 
eelistusega. Lübecki kaupmehed ehitasid endile vägeva Maarja kiriku. Siin on basilikaalne ruum ja kooriümbriskäik, mis ei jää alla piiskoplikule katedraalile - tõeline rikkuse ja mõjukuse manifestatsioon. Lübeck aga oli teenäitajaks teistele hansaliidu linnadele ning ega Tallinn saanud kehvem olla.

Üllatav aga on lugeda (lk 348): "Uusimatel andmetel olid üle värvitud ka Tartu Jaani kiriku terrakotaskulptuurid [...].” Skulptuuride ja nende polükroomiaga tegeles 1950. aastate lõpul ja 1960. aastate algul Olev Prints. Osa tema materjalidest on tallel Muinsuskaitseameti arhiivis ning sealt saab midagi teada ka nende savikujude värvi kohta. ${ }^{9}$

Märkusi ja küsitavusi kogunes üksjagu, kuid mingil juhul ma ei taha paigutada tööd esimeste vasikate hulka. Kahtlemata jääb vaadeldav teos pikaks ajaks meie keskaja-teemaliseks lauaraamatuks, nii nagu oleme ikka ja jälle lahti löönud Hans Kruusi toimetatud 1937. aasta väljaande. Seega pole kahtlust, et uues raamatus esitatud andmed põlistuvad üpris laiade ringide seas, mistõttu latt on ääretult kõrgel.

"Eesti ajalugu II" autorid on kõik tipptasemel medievistid. Selline laiahaardeline ja komplitseeritud struktuuriga teos vajab aga ka tihedamat meeskonnatööd. Sedalaadi raamatu tegemisel on ka teine variant: eesotsas on suur juht ja õpetaja, kes üksipäi dikteerib kogu mängu ja jagab alluvatele käskekorraldusi. Paraku on Anti Selart küll tugev medievist, kuid diktaatoriomadustest jääb tal vist vajaka. Vähemalt selline mulje tekib raamatut lehitsedes.

Kaur Alttoa

${ }_{9}$ Nt Olev Prints, Tartu endise Jaani kiriku lópetamata uurimistööde lópparuanne (Tallinn, 1967), 65 (käsikiri Muinsuskaitseameti arhiivis). 